\title{
ORAL FINDINGS IN PATIENTS WITH REPLACED RENAL FUNCTION - a pilot study
}

\author{
Maria Dencheva $^{1}$, Assya Krasteva ${ }^{1}$, Tzvetelina Gueorgieva ${ }^{2}$, Angelina Kisselova ${ }^{1}$ \\ 1) Department of Imaging and Oral Diagnostic, \\ 2) Department of Conservative Dentistry and Endodontics, \\ Faculty of Dental Medicine, Medical University - Sofia, Bulgaria
}

\section{SUMMARY:}

The aim of this study was to determine the tonguecoating status (using modern index system), the degree of gingival hyperplasia, to register the observed oral lesions in 30 patients with replaced renal function (hemodialysis and renal transplanted).

Key words: patients with replaced renal function, oral manifestation, tongue coating scores;

\section{INTRODUCTION}

In scientific literature the question of oral lesions in patients with end-stage of chronic renal failure is widespread and considered. Most authors agree on the great diversity in clinical oral findings in these patients $(1,3,6,8$, $9,14,15,22,25,27,29,31,38)$. The fact is that non-specific diversity largely might mislead dentists in making accurate diagnosis, if they rely only on oral manifestations.

In Bulgarian literature there are no reports analyzing the frequency of various oral lesions in these patients, which prompted us to realize this study. It is a great interest for us to find the oral changes in people with replaced renal function before the start of project won by our team "Optimisation of complex focal dental sanation of patients with hemodialysis and renal transplantation", which would be oriented us about expected findings in the oral cavity.

\section{METHODS OF STUDY}

We identified the oral status (dental status, oralhygiene level, bleeding from gum papillae, but we don't reflect these indicators in this study) 30 patients with replaced renal function (13 men; 17 women, with middle age of $43 \pm 1,17-62 \%$ of them on hemodialysis and $38 \%$ with renal transplantation).

The first step in clinical examination was the determining the degree of fur, using scale Kojima et al. (table 1), followed by determining the frequency and degree of gingival hyperplasia and registration of existing oral manifestations .
Table 1. Index of Kojima et al. ${ }^{21}$

\begin{tabular}{|l|l|}
\hline index 0 & $\begin{array}{l}\text { lack of accumulation / bloom Visually not } \\
\text { visible coating }\end{array}$ \\
\hline index 1 & $\begin{array}{l}\text { less than } 1 / 3 \text { back of the tongue covered with } \\
\text { a thin coating }\end{array}$ \\
\hline index 2 & $\begin{array}{l}\text { Less than } 2 / 3 \text { tongue covered with thin coating } \\
\text { or less than } 1 / 3 \text { tongue covered with thick }\end{array}$ \\
\hline index 3 & $\begin{array}{l}\text { More than } 2 / 3 \text { tongue covered with thin coating } \\
\text { or less than } 2 / 3 \text { tongue covered with thick } \\
\text { coating }\end{array}$ \\
\hline index 4 & $\begin{array}{l}\text { More than } 2 / 3 \text { tongue covered with thick } \\
\text { coating }\end{array}$ \\
\hline
\end{tabular}

We choose the index of Kojima for two reasons :

- the evaluation of the fur is performed on color photographs, which allow us to take in consideration the view of a second researcher if we suspected a particular case;

- this index system give an account not only of the presence of coating on the tongue, but also its thickness , question that is often neglected in other lingual measurement systems;

In assessing the degree of gingival hyperplasia we used the index of Angelopoulos and Goaz, described by Prof. T. Djemileva $^{(11)}$.

0 - No hyperplasia

1- Hyperplastic gingiva covering the cervical area to one third of the anatomic crown of front teeth ;

2- Hyperplastic gingiva covering the cervical area to two third of the anatomic crown of front teeth ;

3- Hyperplastic gingiva covering the cervical area above two third of the anatomic crown of front teeth ;

\section{RESULTS AND DISCUSSION \\ Lingual index of Kojima et al. :}

$50 \%$ of investigated persons had a value 2 of lingual index of fur (displaying the presence of a thin coating occupying less than two thirds of the dorsal surface of the tongue or reflecting tongue coated with a thick coating of less than $1 / 3$; fig. 2 and fig. 5), 10\% had completely 
covered dorsal lingual surface (corresponding to index 4; figure $1,3,4)$.

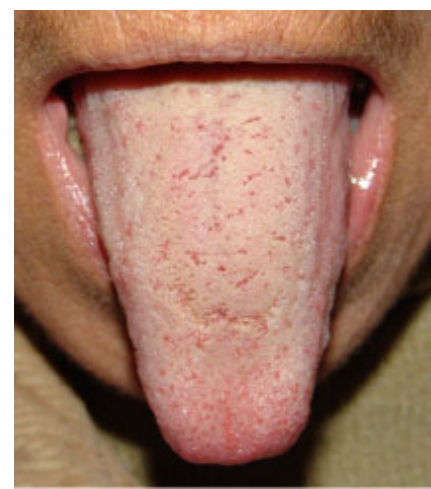

Fig. 1

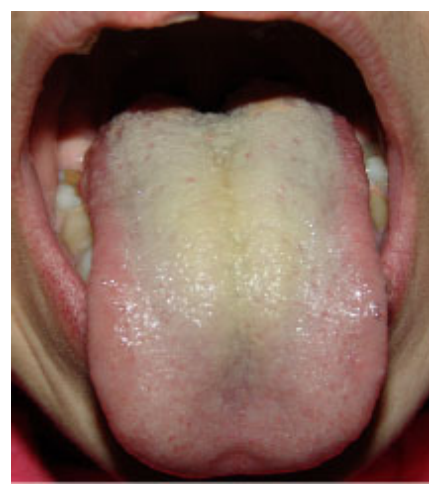

Fig.3

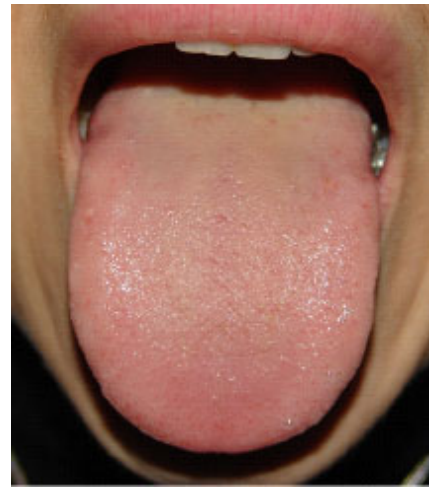

Fig.5

Our data are consistent with data from literature showing that furred tongue is viewed not only in febrile illness, dehydration, diet soft foods but also as an expression of various systemic diseases (Chronic renal failure, diabetes, gastric ulcer and duodenal ulcer, enterocolitis, chronic nephritis, leukemia, glossitis in infectious, febrile conditions, etc.).
A great interest is a comparison of our data with the pattern of Chinese researchers ${ }^{(37)}$, who found correlation between furred lingual areas and the presence of systemic disease .

According to them, in renal diseases furred zones of the tongue should be extended to the rear (oesophageal) part (fig.6). Our results, although pilot show that in over $60 \%$ of the examined persons this area was always furred and only four individuals were not .

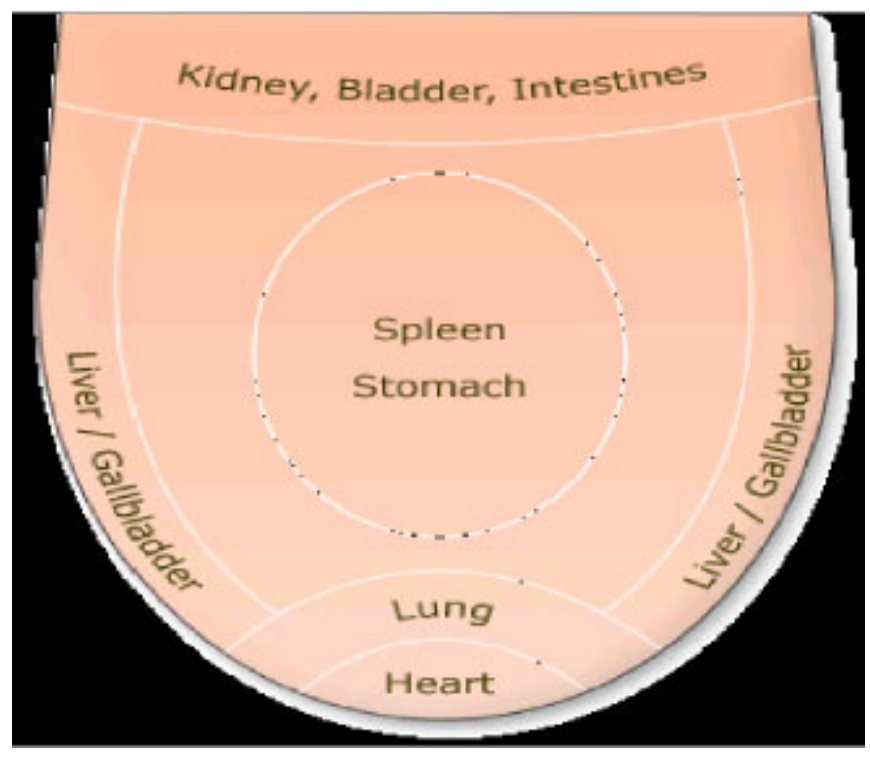

Fig. 6.

\section{Oral findings}

Oral mucosal findings reported in chronic renal failure with the exception of uremic stomatitis $(19,30)$ are unusual and quite varied, as a result of main disease and taking medications: white plates, macula and the nodules, erythematous plaques, fibro-epithelial polyps, ulcers, geographic tongue, lichen planus, black fiber language papilloma $(4,13,14,18,20,23)$. It is often viewed pale oral mucosa due to anemia, but also red-orange recolor of skin

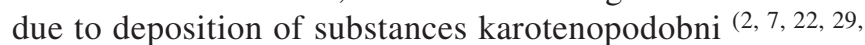
34,38 ).

In our study we observed some of the described findings (probably due to the small number of responden), particulary geographic tongue, migratory erythema (lingua geographica, glositis exfoliativa marginalis, erythema migrans) in three patients (fig. 7, 8, 9), fibrous hairy tongue (lingua nigra/alba villosa, hairy tongue) on one of the subjects (fig. 10). 


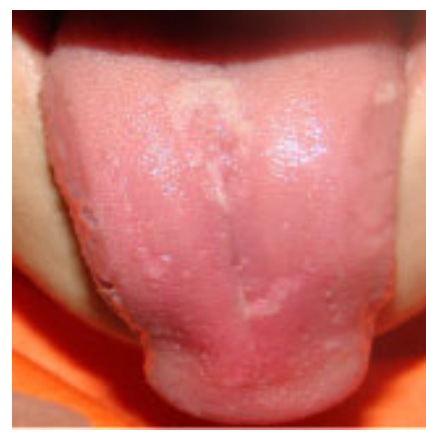

Fig. 7.

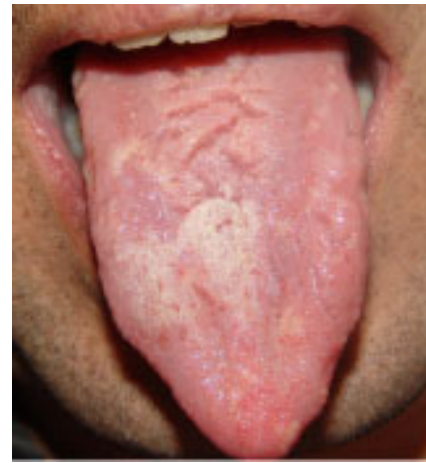

Fig. 9.

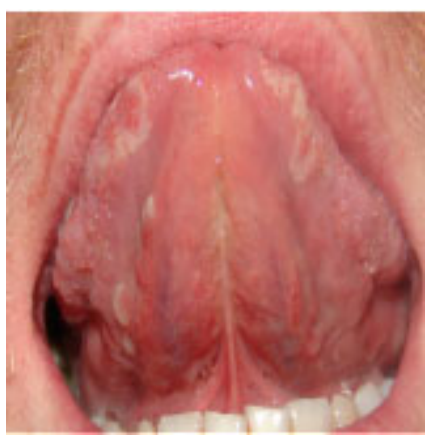

Fig.8

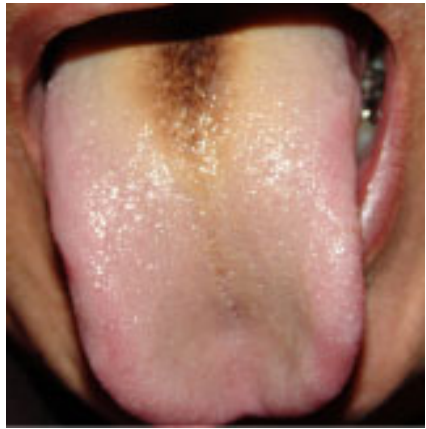

Fig.10
We signed and one case of granulomatous helium (cheilitis granulomatosa), combined with exfoliative cheilitis (cheilits exfoliativa) (fig.11).

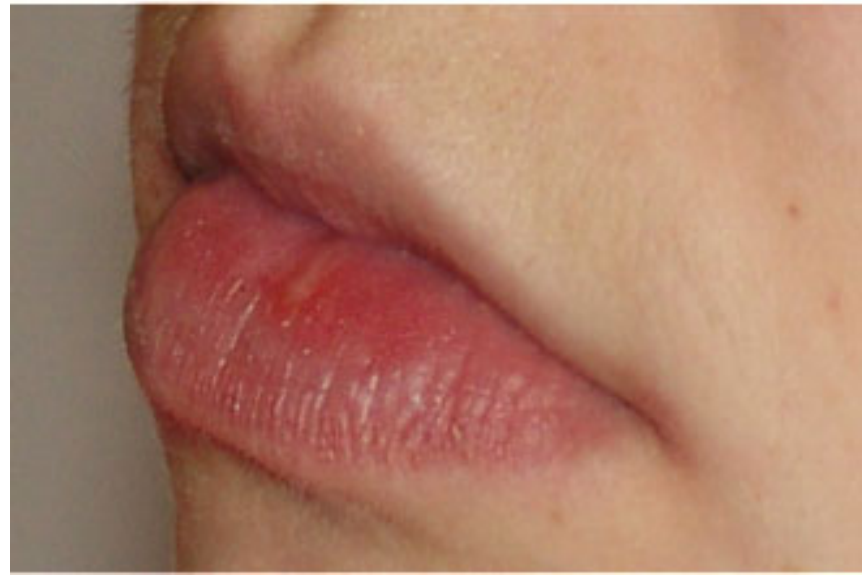

fig. 11.

\section{Gingival hyperplasia}

One of the most typical findings in patients with end-stage renal failure is gingival hyperplasia (drugi indused gingival overgrowth), which mechanism of occurrence is multifactorial and still unknown . Taking antihypertensive drugs and immunosuppressive drugs give its impact in the oral cavity $(5,10,12,16,17,32,33,36)$. Such gingival expansion occurred more frequently in the early post-transplant period (4 months) and in combination with low oral hygiene ${ }^{(11,28,35)}$.

Of the studied patients gingival hyperplasia was recorded only in two with renal transplantation, which immunosuppressive therapy was accompanied with the intake of antihypertensive drugs-Corinfar retard, Cordaflex (fig. 12) and transplantation made more than three years

This fact quite surprised us because we expected a higher incidence of people with medicated hyperplastic gingivitis. In both patients the index of Angelopoulos and Goaz was with value 1 .

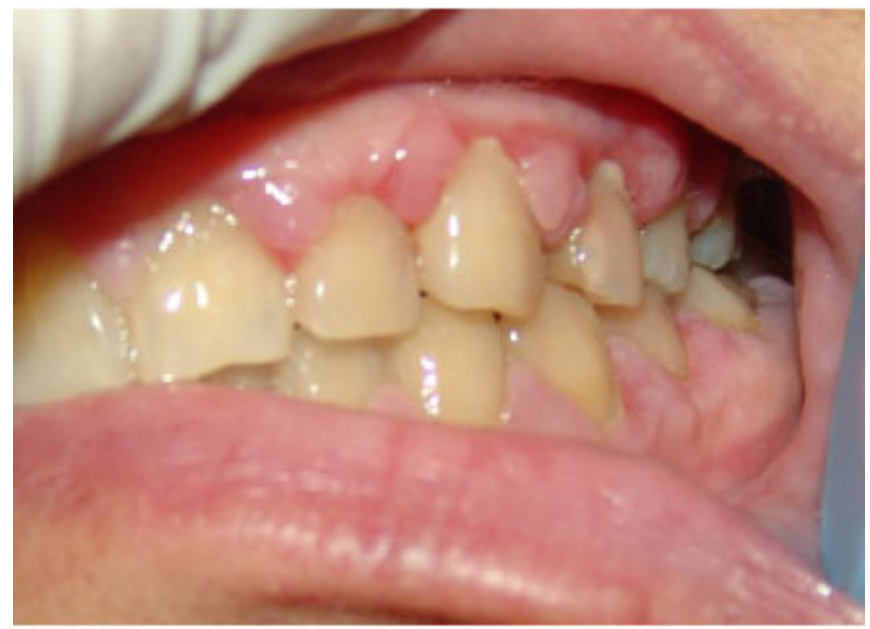

fig. 12.

\section{IN CONCLUSION}

Our pilot results confirm that oral manifestations observed in patients with replaced renal function, although non-specific cause subjective complaints of patients and this character determines the need for additional dental intervention although we didn't found a wide variety of oral manifestations .

It is undeniable that these patients burdened by his primary renal disease have subjective complaints of the oral cavity, which further suppresses them. This necessitates their periodic meeting with dentists, although the data in the scientific literature about caries-resistance of the dentition of children and adults on dialysis $(3,13,26)$.

We hope in the course of our work with patients with transplantation and those on dialysis (the project is for the whole country) to expand the spectrum of the data and to compare the incidence of oral lesions in different countries. 


\section{REFERENCES:}

1. Antoniades DZ, Markopoulus AK, Andreadis D, et al. Ulcerativ uremic stomatitis associated with untreated chronic renal failure: report of a case and review of the literature. Oral Surg Oral Med Pathol Oral Radiol Endod. 2006 May, 101 (5): 608-13.

2. Azmanova, V., et al. .Atlas na zaboljavanijata na ustnata ligaviza.Medizina I fizkultura, S. 1992. (bul)

3. Bayraktar G, Kurtulus I, Duraduryan A, et al. Dental and periodontal findings in hemodyalisis patients. Oral Disiase, 2007; 13: 393-7.

4. Chuang SF, Sung JM, Kuo SC, Huang JJ, Lee SY. Oral and dental manifestations in diabetic and nondiabetic uremic patients receiving hemodialysis. OOOOE, 2005, 99: 6; 689-695.

5. Craig, R. G. Interactions between chronic renal disease and periodontal disease. Oral Dis, 2008 Jan; 14 (1): 1-7.

6. Davidovich E, Davidovits $\mathrm{M}$, Eidelman E, Schvarz Z, Bimstein E. Pathophysiology, therapy, and oral implications of renal failure in children an adolescents: an update. Pediatr Dent., 2005 Mar-Apr; 27 (2): 98-106.

7. Davidovich E, Z. Schwarz, M. Davidovitch, E. Eidelman, E. Bimstein. Oral findings and periodontal status in children, adolescents and young adults suffering from renal failure. J Clin Periodontol, 2005; 32: 1076-1082.

8. De la Rosa Garcia E, et al. Oral mucosa symptoms, signs and lesions, in end stage renal disease and non end - stage renal disease diabetic patients. Med Oral Patol Oral Cir Bucal., 2006 Non 1; 11 (6): E 467-73, Synder, S., B. Pendrgraph. Detection and evaluation of chronic kidney disease. Am Fam Physican, 2005 Nov 1; 72 (9): 1723-32.

9. De Rossi, S., M. Glick. Dental considerations for the patient with renal disease receiving hemodialysis. JADA, vol. 127 , 1996, 211-219.

10. Djemileva T, T. Bolyarova. Gingivalno razrastvane pri sistemna terapia $\mathrm{s}$ calzievi antagonisti, imunosupresori I hiddantoini. „ACER”, S., 2007, 118.2 (bul)

11. Djemileva T. Zaboljavanija na parodonta. „ACER”, S., 1999, 3 (bul)
12. Ellis JS, Seymour RA, Taylor JJ, Thomason JM. Prevalence of gingival overgrowth in transplant patients immunosuppressed with tacrolimus. J Clin Periodontol, 2004, 31: 126-131.

13. Ertugrul, F., C. Elbek-Cubukcu, E. Sabah, S. Mir. The oral health status of children undergoing hemodialisis treatment. Turk J Pediat, 2003: 45; 108-113.

14. Franca, C. M., M. Domingues-Martins, A. Volpe åt al. Severe oral manifestations of chronic graft-vs.-host disease. JADA ,Vol. 132, August 2001.

15. Gavalda, C., J. Bagan, C. Scully, F. Silvestre, M. Milian, Y. Jimenez. Renal haemodialysis patients: oral, salivary, dental and periodontal findings in 105 adult cases. Oral Dis, 1999; 5: 299-302.

16. Gera, I., T. Keglevich. A case history of a kidney transplant patient with ciclosporin - induced gingival overgrowth combined with chronic periodontitis. Perio, 2007; 12: 287-293.

17. Hassell, T. M., A. F. Hefti. Druginduced gingival overgrowth: old problem, new problem. Crit Rev Oral Biol Med, 1991; 2: 103-37.

18. Jaffe, E. C., G. J. Roberts, C. Chantler, J. E. Carter. Dental findings in chronic renal failure. Br Dent J, 1986; 160: 18-20.

19. Kellett, M. Oral white plaques in uraemic patients. B Dent J, 1983; 154: 366.

20. Klassen, J. T., B. M. Krasko. The dental health status of dialysis patients. J Can Dent Assoc, 2002; 68: 34-8.

21. Kojima, K. Clinical studies on the coated tongue. Japanese J Oral Maxilofac Sur, 31, 1985: 1659-1676.

22. Long, R., L. Hlousek, J. Doyle. Oral manifestations of systemic diseases. Dermatol Clin, 1998, 65: 309-315.

23. Mccartan, B. E., C. E. Mccreary. Oral lichenoid drug eruptions. Oral Dis, 1997; 3: 58-63.

24. Nakhjavani, Yahya B., Ali Bayramy. The dental and oral status of children with chronic renal failure. J Indian Soc Pedod Prev Dent, March 2007: 7-9.

25. Naugle, K., M. L. Darby, D. B. Bauman, L. T. Lineberger, R. Powers. The oral health status of individuals on renal di- alysis. Ann Periodontol, 1998, 3: 197-205.

26. Peneva, M., et al..Zaben caries pri deza s hronihna babrehna nedostatahnost. Stomatologia., Ñ., 3, 1989, 6-9.

27. Peneva,M., et al.Oralen status pri deza s hronihna babrehna nedostatahnost. Stomatologia, Ñ., 3, 1988, 72-76.

28. Pernu, H. E., L. M. Pernu, K. R. Huttunen, P. A. Nieminen, M. L. Knuuttila. Gingival overgrowth among renal transplant recipients related to immunosuppressive medication and possible local background factors. J Periodontol., 1992; 63: 548-53.

29. Proctor, R., N. Kumar, A. Stein, D. Moles, S. Porter. Oral and dental aspects of chronic renal failure. J Dent Res., 2005 Mar; 84 (3): 199-208.

30. Ross, W. F., P. L. Salisbury. Uremic stomatitis associated with undiagnosed renal failure. Gen Dent, 1994; 9/10: 410-412.

31. Seymour, R. A., J. M. Thomason, A. Nolan. Oral lesions in organ transplant patients. J Oral Path Oral Med, 1997; 26: 297-304.

32. Seymour, R., D.J. Jacobs. Cyclosporin A and the gingival tissues. Journal of clinical periodontology, 1992; 19: $1-11$.

33. Somacarrera, M. L., G. Hernandez, J. Acero, B. S. Moskow. Factors related to the incidence and severity of cyclosporine - induced gingival overgrowth in transplant patients. A longitudinal study. J Periodontol, 1994; 65: 671-5.

34. Summers, S. A., W. M. Tilakaratne, F. Fortune, N. Ashman. Renal disease and the mouth. Am J Med, 2007; 120 (7): 56873.

35. Taylor, B. A. Management of drug - induced gingival enlargement. Australien Prescriber, 2003, vol. 26, 1.

36. Thomason, J. M., R. A. Seymour. The prevalence and severity of cyclosporin and nifedipine - induced gingival overgrowth. J Clin Periodontol, 1993; 20: 37-40.

37. Wu, J., Y. Zhang, J. Bai. Tongue area extraction in tongue diagnosis of traditional chinese medicine. Conf Proc IEEE Eng Med Biol Soc, 5, 2005: 4955-4957.

38. Zlatkov, N., et al. Kojni projavi pri vatresni bolesti.Volkohim, Ñ., 1994, 263.4

\section{Address for correspondence:}

Dr Maria Dencheva

Department of Imaging and oral diagnostic, Faculty of Dental Medicine, Medical University - Sofia; 1, Sv. Georgi Sofiiski bul., 1000 Sofia, Bulgaria;

E-mail: jivena@abv.bg 